\title{
Prevalence of depression and associated factors among hemodialyzed patients in Jazan area, Saudi Arabia: a cross-sectional study
}

\author{
Asim Othayq \\ Department of Health Affairs, Saudi Arabia Ministry of Health, Riyadh, Saudi Arabia, and \\ Abdulwahab Aqeeli \\ Department of Family and Community Medicine, Jazan University, Jazan, Saudi Arabia
}

\begin{abstract}
Purpose - This study aims to evaluate the prevalence of depression and associated risk factors among patients on hemodialysis in Jazan area, Saudi Arabia.

Design/methodology/approach - The study was conducted on 211 randomly selected hemodialysis patients in Jazan area, Saudi Arabia, using an observational cross-sectional design. Patients were screened for depressive symptoms using the depression, anxiety and stress scale 42 (DASS-42). Descriptive statistics were used to present sociodemographic data. Multiple logistic regression was implemented to identify the predictors of depression. Data were entered and analyzed using SPSS 22.0 software.

Findings - The study found the overall prevalence of depression among patients on hemodialysis to be 43.6 per cent. Of them, 12.8 per cent were mildly depressed, 15.6 per cent were moderately depressed and 15.1 per cent fell in the severe or extremely severe category. Depression was significantly associated with marital status, education level and the presence of sleep disturbances. The study indicates a high prevalence of depressive symptoms among patients on hemodialysis in Jazan. A higher rate of depressive symptoms was observed in currently unmarried, lowereducated patients and those with sleep disturbance.
\end{abstract}

Originality/value - Periodic evaluation of patients on hemodialysis for depression is needed to allow for early intervention.

Keywords Saudi Arabia, Depression, Hemodialyzed patients, DASS-42, kidney disease, hemodialysis

Paper type Research paper

\section{Introduction}

End-stage renal disease (ESRD) is a progressive and irreversible loss of kidney function over a long period and sufficiently severe to require maintenance dialysis or kidney transplantation to maintain health or life (Müller et al., 2010). Like numerous chronic diseases, ESRD may influence the psychological status of the patients (Feroze et al., 2010). Psychiatric illnesses, including depression in patients with ESRD, have its effect on the morbidity and healthcare costs among patients with ESRD. The term "psychonephrology" has been introduced by Levy to refer to psychiatric problems of patients suffering from chronic kidney disease and particularly those with kidney failure on maintenance dialysis or who underwent transplantation (Levy, 2008).

Depression is considered as the most common psychological illness among hemodialysis patients. Among the general population, the prevalence of major depression ranged between 1.1 and 23 per cent (Weissman et al., 1996). However, among ESRD patients, it ranged between 20 and 30 per cent (Chilcot

The current issue and full text archive of this journal is available on Emerald Insight at: https://www.emerald.com/insight/2036-7465.htm

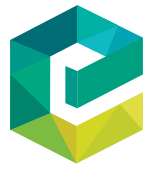

Mental Illness

12/1 (2020) 1-5

Emerald Publishing Limited [ISSN 2036-7465]

[DOI 10.1108/MIJ-02-2020-0004] et al., 2008) and may reach up to 60.5 per cent (Kao et al., 2009). In Saudi Arabia, the prevalence of depression among ESRD patients on hemodialysis ranged between 23.3 and 83.5 per cent (Turkistani et al., 2014; Saeed et al., 2012; AlDukhayel, 2015; Joshwa et al., 2012).

Despite the high incidence of depression among hemodialysis patients, its diagnosis is often overlooked (Cukor et al., 2007). Diagnosis of depression in these patients is essential as depression in chronic diseases, in general, has been associated with lack of adherence to the therapy, high suicidal

\footnotetext{
(C) Asim Othayq and Abdulwahab Aqeeli. Published by Emerald Publishing Limited. This article is published under the Creative Commons Attribution (CC BY 4.0) licence. Anyone may reproduce, distribute, translate and create derivative works of this article (for both commercial and non-commercial purposes), subject to full attribution to the original publication and authors. The full terms of this licence may be seen at: http://creativecommons.org/licences/by/4.0/legalcode

Acknowledgments: The authors acknowledge the assistance provided by the staff of hemodialysis centers and Directorate of Health Affairs in Jazan region.

Author contributions: All authors contributed equally to conceptualize, design, analyze the data, draft the article and approve the final version of the work.

Declarations of interest: Authors have no conflict of interest in this work to report.

Funding: This research did not receive any specific fund.
}

Received 19 February 2020

Revised 19 February 2020

Accepted 19 February 2020 
tendencies and poor survival rates (Katon et al., 2007; Diefenthaeler et al., 2008; Hedayati et al., 2005; Kimmel et al., 1993). Moreover, a strong association has been observed between depression and longitudinal outcomes among hemodialysis patients, including poor adherence to treatment, impaired quality of life and higher mortality rates (Drayer et al., 2006; Li et al., 2016). In addition, depression among hemodialysis patients is associated with higher rates of hospital admission and a greater likelihood of emergency department (ER) visits (Tavallaii et al., 2009; Hedayati et al., 2008).

Few studies that have identified the prevalence of depression, along with their associated factors, among patients on hemodialysis in the Kingdom of Saudi Arabia. However, there is limited information regarding the prevalence of depression and its associated risk factors among patients on hemodialysis in the Southern area in Saudi Arabia. Therefore, this study aimed to estimate the prevalence of depression and its associated risk factors among patients on hemodialysis in Jazan area, Saudi Arabia.

\section{Material and methods}

\section{Study area, design and population}

A cross-sectional study was conducted among patients on hemodialysis in Jazan province, one of the 13 provinces of Saudi Arabia. It is located in the southwestern border of the country. It has a total population of approximately 1.5 million according to the 2015 census. Jazan has eight governmental hemodialysis centers serving 842 registered patients at the time of the study.

\section{Sampling method and sample size}

A sample of 229 out of 842 registered hemodialysis patients was recruited by systematic random sampling. The sample size was calculated based on the following parameters; $P=23.3$ per cent (the lowest reported depression prevalence among hemodialysis patients in Saudi Arabia), 95 per cent confidence level, a margin of error below 5 per cent and nonresponse rate of 20 per cent. Patients were recruited from three randomly selected out of eight governmental hemodialysis centers in Jazan.

\section{Data collection and study instrument}

Data were collected by trained nurses through face-to-face interview using an Arabic questionnaire while patients were waiting for their dialysis session. The questionnaire was composed of two main parts; the first part contained patient's demographics (age, gender, marital status, living status, education, employment status), comorbid history (diabetes and hypertension), history of sleep disturbance, current smoking status, physical activity status and duration of dialysis. The second part contained depression questions adapted from the Arabic version of the depression, anxiety and stress scale 42 (DASS-42). The DASS-42 consists of a 42-item self-report inventory designed to screen for the presence and severity of symptoms of depression, anxiety and stress among people as young as 18 (Lovibond and Lovibond, 1995). This scale was psychometrically validated to the Arabic culture (Moussa et al., 2017). This screening and outcome measure reflects the experience of the person over the previous seven days.
Depression scale contained 14 questions presented as a fourpoint Likert scale, with 0 being does not apply and 3 being very applicable/applies most of the time. The scores were calculated by summing the scores of the depression questions.

\section{Data analysis and management}

Data were collected and verified by hand before data entry. The statistical Package for Social Sciences (SPSS) software version 22.0 (SPSS Inc., Chicago, IL, USA) was used for data entry and analysis. Descriptive statistics and inferential statistics were applied. Sociodemographic factors were presented by frequency and percentage, except for age and the duration of hemodialysis, which were presented by mean and SD. Univariate analysis to determine the association of each variable with depression was also implemented. Finally, multivariate logistic regression analysis was performed to identify predictors of depression among patients after controlling for confounders. The results were expressed as adjusted odds ratio and 95 per cent confidence intervals. All statistical tests were two-sided, and a $p$-value less than 0.05 was considered statistically significant.

\section{Ethical consideration}

This study was conducted in accordance with the ethical principles within the Kingdom of Saudi Arabia. Ethical approval was obtained from the Faculty of Medicine Ethical Committee at Jazan University. The privacy and confidentiality of the data were maintained throughout the study period. Patients read, understood and signed informed consent.

\section{Results}

A total of 211 hemodialysis patients participated in the study (response rate $=92.1$ per cent). Their sociodemographic and health-related characteristics are summarized in Table 1. Patients' age ranged between 16 and 90 years (mean \pm SD: $48.5 \pm 14.8$ ). Almost half of them (47 per cent) were in the age group 31-50 years, whereas 17.5 per cent of them were aged over 60 years. Female patients represent 59.7 per cent, with almost two-thirds of them (66.4 per cent) being married. Majority of patients live with others (95.7 per cent) and were not working (85.3 per cent). Regarding educational level, 60.7 per cent of the participants were illiterate, whereas 9.4 per cent were at least university graduates. The prevalence of current smoking, diabetes and hypertension among patients were 4.7, 23.2 and 68.2 per cent, respectively. Moreover, 55.9 per cent of the patients had sleep disturbances, and 31.3 per cent were physically active. The duration of hemodialysis ranged between one month and 31 years with a mean of fiveyears and a standard deviation of 5.1. Approximately, 27.5 per cent of the patients had hemodialysis duration that exceeded five years, whereas 20.9 per cent of them had a duration of one year or less of hemodialysis. Depression was more likely to be reported among patients who were female (50.8 per cent, $p=0.010$ ), divorced or widowed (72.4 per cent, $p=0.001$ ), illiterate (53.1 per cent, $p=0.002$ ), had sleep disturbance (57.6 per cent, $\mathrm{p}<$ 0.001 ) and were physically inactive (49.7 per cent, $p=0.009$ ). Smoking history, histories of diabetes and hypertension and 
Table I Sociodemographic and health-related characteristics of patients on hemodialysis in Jazan area

\begin{tabular}{|c|c|c|c|c|c|}
\hline Characteristics & $n(\%)$ & $\begin{array}{c}\text { Depression } \\
n(\%)\end{array}$ & $\begin{array}{c}\text { Test } \\
\text { value } \\
\left(\chi^{2}\right)\end{array}$ & $d f$ & $p$-value \\
\hline \multicolumn{6}{|l|}{ Gender } \\
\hline Male & $85(40.3)$ & $28(32.9)$ & 6.58 & 1 & 0.010 \\
\hline Female & $126(59.7)$ & $64(50.8)$ & & & \\
\hline \multicolumn{6}{|l|}{ Marital status } \\
\hline Married & $140(66.4)$ & $50(35.7)$ & 14.03 & 2 & 0.001 \\
\hline Single & 42 (19.9) & $21(50.0)$ & & & \\
\hline Divorced/widowed & $29(13.7)$ & $21(72.4)$ & & & \\
\hline \multicolumn{6}{|l|}{ Working status } \\
\hline Working & 31 (14.7) & $10(32.3)$ & 1.90 & 1 & 0.168 \\
\hline Not working & $180(85.3)$ & $82(45.6)$ & & & \\
\hline \multicolumn{6}{|l|}{ Educational level } \\
\hline Illiterate & $128(60.7)$ & $68(53.1)$ & 12.40 & 2 & 0.002 \\
\hline $\begin{array}{l}\text { Secondary school } \\
\text { or below }\end{array}$ & $63(29.9)$ & $17(27.0)$ & & & \\
\hline University or above & $20(9.4)$ & $7(35.0)$ & & & \\
\hline \multicolumn{6}{|l|}{ Cigarette smoking } \\
\hline Smoker & $9(4.3)$ & $2(20.0)$ & 2.86 & 2 & 0.239 \\
\hline Ex-smoker & $26(12.3)$ & $10(38.5)$ & & & \\
\hline Non-smoker & $176(83.4)$ & $80(45.7)$ & & & \\
\hline \multicolumn{6}{|l|}{ Diabetes } \\
\hline Yes & $49(23.2)$ & $21(42.9)$ & 0.01 & 1 & 0.904 \\
\hline No & $162(76.8)$ & $71(43.8)$ & & & \\
\hline \multicolumn{6}{|l|}{ Hypertension } \\
\hline Yes & $144(68.2)$ & $62(43.1)$ & 0.06 & 1 & 0.815 \\
\hline No & $67(31.8)$ & $30(44.8)$ & & & \\
\hline \multicolumn{6}{|l|}{ Sleep disturbance } \\
\hline Yes & $118(55.9)$ & $68(57.6)$ & 21.42 & 1 & $<0.001$ \\
\hline No & $93(44.1)$ & $24(25.8)$ & & & \\
\hline \multicolumn{6}{|l|}{ Physical activity } \\
\hline Yes & $66(31.3)$ & $20(30.3)$ & 6.91 & 1 & 0.009 \\
\hline No & $145(58.7)$ & $72(49.7)$ & & & \\
\hline
\end{tabular}

duration of hemodialysis were not significantly associated with depression.

The mean score of depression symptoms was at normal level (Table 2). The symptoms of depression were reported among 43.6 per cent of hemodialysis patients. The prevalence of mild,

Table II Prevalence and score severity ratings of depressive symptoms among patients on hemodialysis in Jazan area

\begin{tabular}{lcc}
\hline Category & Score severity ratings & Frequency (\%) \\
\hline Normal & $0-9$ & $119(56.4)$ \\
Mild & $10-13$ & $27(12.8)$ \\
Moderate & $14-20$ & $33(15.6)$ \\
Severe & $21-27$ & $26(12.3)$ \\
Extremely severe & $28+$ & $6(2.8)$ \\
Mean \pm SD & & $9.6 \pm 8.5$ \\
\hline
\end{tabular}

moderate, severe and extremely severe symptoms of depression were $12.8,15.6,12.3$ and 2.8 per cent, respectively.

Table 3 presents the results of the multivariate logistic regression analysis. The analysis revealed that single $(\mathrm{OR}=$ 3.04, 95 per cent CI: $1.32-6.97, p=0.009)$ and divorced/ widowed marital status $(\mathrm{OR}=3.35,95$ per cent $\mathrm{CI}$ : $1.29-8.68$, $p=0.013)$ strongly predicted the risk of depression. Other predictors of risk for depression included secondary school education, which significantly lowered risk for depression $(\mathrm{OR}=0.36,95$ per cent $\mathrm{CI}: 0.16-0.80, p=0.012)$ and sleeping disturbances, which was the strongest predictor for the risk of depression. $(\mathrm{OR}=3.75,95$ per cent $\mathrm{CI}: 2.01-7.27, p=0.000)$.

\section{Discussion}

The aim of this study was to identify the prevalence of depression and related risk factors among patients on hemodialysis in Jazan region, Saudi Arabia. Our study revealed that depression, regardless of its severity, was present among 43.6 per cent of the patients on hemodialysis. This estimate is higher than that reported by Turkistani et al. in their study in Makkah (23.3 per cent) using the Hospital Anxiety and Depression Scale (HADS) (Turkistani et al., 2014). On the other hand, it was lower than that observed by Saeed and his colleagues on patients with ESRD on hemodialysis using the Beck's Depression Inventory (BDI-II) scoring (75 per cent) (Saeed et al., 2012). Globally, the prevalence rate of depression among patients on hemodialysis ranged between 20 and 60.5 per cent (Chilcot et al., 2008; Kao et al., 2009) This difference in the prevalence of depression could be attributed to different tools used for estimating the prevalence of depression as well as sample characteristics.

In studying the sociodemographic factors, marital status, education level and sleep disturbances were associated with depression. Our findings showed that being unmarried was highly correlated with increased depression prevalence rate. This is the opposite to what Saeed et al. reported in their study where married patients were more likely to have depression (Saeed et al., 2012). This difference could be attributed to the fact that married individuals hold more responsibility to their families. On the other hand, gender and physical activity were not correlated with depression contradicting previous studies (Li et al., 2016; Fischer et al., 2010; Chiang et al., 2013; Bayat et al., 2011).

There is lack of evidence on the relationship between sleep disturbances and depression among ESRD patients. However, a recently online published article has found that insomnia is related to depression among hemodialysis patients in Indonesia (Lufiyani et al., 2019). Furthermore, insomnia and sleep complaints were common among ESRD patients on hemodialysis (Walker et al., 1995; Hanly, 2004; Parker, 2003). Additionally, a study of the general population suggested a causative link between insomnia and depression (Gillin, 1998). Moreover, a meta-analysis by Chiara et al. found a twofold increase in the risk of depression in healthy individuals (Baglioni et al., 2011). In our study, the presence of sleep disturbance was significantly associated with depression. Patients who had sleeping disturbance were at almost a fourfold increased risk for depression compared to those without sleep disturbances. Consequently, it is clinically significant for 
Table III Multivariate logistic regression analysis of risk factors for depression among patients on hemodialysis in Jazan area

\begin{tabular}{|c|c|c|c|c|}
\hline \multirow[b]{2}{*}{ Characteristics } & \multirow{2}{*}{$\begin{array}{l}\text { Adjusted } \\
\text { odds ratio }\end{array}$} & \multicolumn{2}{|c|}{$\begin{array}{c}95 \% \text { confidence } \\
\text { interval }\end{array}$} & \multirow[b]{2}{*}{$p$-value } \\
\hline & & Upper & Lower & \\
\hline \multicolumn{5}{|l|}{ Gender } \\
\hline Male $(n=85)$ & 1 & & & \\
\hline Female $(n=126)$ & 0.95 & 0.43 & 2.11 & 0.894 \\
\hline \multicolumn{5}{|l|}{ Marital status } \\
\hline Married $(n=140)$ & 1 & & & \\
\hline Single $(n=42)$ & 3.04 & 1.32 & 6.97 & 0.009 \\
\hline $\begin{array}{l}\text { Divorced/widowed } \\
(n=29)\end{array}$ & 3.35 & 1.29 & 8.68 & 0.013 \\
\hline $\begin{array}{l}\text { Educational level } \\
\text { Illiterate }(n=128)\end{array}$ & 1 & \multicolumn{2}{|c|}{ Educational level } & \\
\hline $\begin{array}{l}\text { Secondary school or } \\
\text { below }(n=63)\end{array}$ & 0.36 & 0.16 & 0.80 & 0.012 \\
\hline $\begin{array}{l}\text { University or above } \\
(n=20)\end{array}$ & 0.67 & 0.23 & 1.96 & 0.461 \\
\hline \multicolumn{5}{|l|}{ Smoking history } \\
\hline Smoker $(n=10)$ & 0.57 & 0.09 & 3.56 & 0.547 \\
\hline Ex-smoker $(n=26)$ & 1.30 & 0.43 & 3.93 & 0.643 \\
\hline Non-smoker $(n=175)$ & 1 & & & \\
\hline \multicolumn{5}{|l|}{ Diabetes mellitus } \\
\hline Yes $(n=49)$ & 0.93 & 0.43 & 1.99 & 0.843 \\
\hline No $(n=162)$ & 1 & & & \\
\hline \multicolumn{5}{|l|}{ Hypertension } \\
\hline Yes $(n=144)$ & 0.89 & 0.44 & 1.79 & 0.745 \\
\hline No $(n=67)$ & 1 & & & \\
\hline \multicolumn{5}{|l|}{ Sleep disturbance } \\
\hline Yes $(n=118)$ & 3.75 & 1.90 & 7.37 & 0.000 \\
\hline No $(n=93)$ & 1 & & & \\
\hline \multicolumn{5}{|l|}{ Physical activity } \\
\hline Yes $(n=66)$ & 0.79 & 0.39 & 1.63 & 0.530 \\
\hline No $(n=145)$ & 1 & & & \\
\hline
\end{tabular}

patients on hemodialysis to be screened for sleep problems to protect them from depression.

From the estimates mentioned above, it is clear that depression is increasingly prevalent among patients on hemodialysis. Hence, the implications of these results are very important for early intervention to limit the impact of depression and improve the quality of life for those patients. However, the recognition and management of depression are still suboptimal in routine care of those patients (Hedayati et al., 2005). Therefore, healthcare providers must be aware of the existence of depression among patients on hemodialysis and be able to provide standard care procedures to them and implement early screening to identify and refer high-risk cases (Fischer et al., 2010).

\section{Limitations}

The authors acknowledge the following limitations of the present study. First, this study used a cross-sectional design; hence, we cannot infer causality from our findings. Second, the sleep disturbance and physical activity were examined with only a single-item question rather than using structured scale, which may have been more robust. Finally, the DASS -42 scale is used to screen for depressive symptoms rather than make a diagnosis of depression; therefore, the current findings should be interpreted with caution.

\section{Conclusions}

Depression was highly prevalent among patients on hemodialysis in Jazan region, Saudi Arabia. Current unmarried, lower-educated patients as well as those having sleep disorders were more likely to have depression. Our findings draw attention to the importance of screening hemodialyzed patients for depression to intervene early.

\section{References}

AlDukhayel, A. (2015), "Prevalence of depressive symptoms among hemodialysis and peritoneal dialysis patients", International fournal of Health Sciences, Vol. 9 No. 1, p. 9.

Baglioni, C., Battagliese, G., Feige, B., Spiegelhalder, K., Nissen, C., Voderholzer, U., Lombardo, C. and Riemann, D. (2011), "Insomnia as a predictor of depression: a metaanalytic evaluation of longitudinal epidemiological studies", Fournal of Affective Disorders, Vol. 135 Nos 1/3, pp. 10-19, doi: 10.1016/j.jad.2011.01.011.

Bayat, N., Alishiri, G.H., Salimzadeh, A., Izadi, M., Saleh, D.K., Lankarani, M.M. and Assari, S. (2011), "Symptoms of anxiety and depression: a comparison among patients with different chronic conditions", fournal of Research in Medical Sciences: The Official Fournal of Isfahan University of Medical Sciences, Vol. 16 No. 11, p. 1441.

Chiang, H.H., Livneh, H., Yen, M.L., Li, T.C. and Tsai, T.Y. (2013), "Prevalence and correlates of depression among chronic kidney disease patients in Taiwan", BMC Nephrology, Vol. 14 No. 1, p. 78.

Chilcot, J., Wellsted, D., Da Silva-Gane, M. and Farrington, K. (2008), "Depression on dialysis", Nephron Clinical Practice, Vol. 108 No. 4, pp. c256-64.

Cukor, D., Cohen, S.D., Peterson, R.A. and Kimmel, P.L. (2007), "Psychosocial aspects of chronic disease: ESRD as a paradigmatic illness", fournal of the American Society of Nephrology, Vol. 18 No. 12, pp. 3042-3055.

Diefenthaeler, E.C., Wagner, M.B., Poli-de-Figueiredo, C.E., Zimmermann, P.R. and Saitovitch, D. (2008), "Is depression a risk factor for mortality in chronic hemodialysis patients?", Revista Brasileira de Psiquiatria, Vol. 30 No. 2, pp. 99-103.

Drayer, R.A., Piraino, B., Reynolds, I.I.C.F., Houck, P.R., Mazumdar, S., Bernardini, J., et al. (2006), "Characteristics of depression in hemodialysis patients: symptoms, quality of life and mortality risk", General Hospital Psychiatry, Vol. 28 No. 4, pp. 306-312.

Feroze, U., Martin, D., Reina-Patton, A., Kalantar-Zadeh, K. and Kopple, J.D. (2010), "Mental health, depression, and anxiety in patients on maintenance dialysis", Iranian fournal of Kidney Diseases, Vol. 4 No. 3. 
Fischer, M.J., Kimmel, P.L., Greene, T., Gassman, J.J., Wang, X., Brooks, D.H., et al. (2010), "Sociodemographic factors contribute to the depressive affect among African Americans with chronic kidney disease", Kidney International, Vol. 77 No. 11, pp. 1010-1019.

Gillin, J.C. (1998), "Are sleep disturbances risk factors for anxiety, depressive and addictive disorders?", Acta Psychiatrica Scandinavica, Vol. 98 No. S393, pp. 39-43.

Hanly, P. (2004), "DAILY HEMODIALYSIS - SELECTED TOPICS: Sleep apnea and daytime sleepiness in end-stage renal disease", Seminars in Dialysis, Wiley Online Library, pp. 109-114.

Hedayati, S.S., Bosworth, H.B., Briley, L.P., Sloane, R.J., Pieper, C.F. and Kimmel, P.L. et al. (2008), "Death or hospitalization of patients on chronic hemodialysis is associated with a physician-based diagnosis of depression", Kidney International, Vol. 74 No. 7, pp. 930-936.

Hedayati, S.S., Grambow, S.C., Szczech, L.A., Stechuchak, K.M., Allen, A.S. and Bosworth, H.B. (2005), "Physiciandiagnosed depression as a correlate of hospitalizations in patients receiving long-term hemodialysis", American Fournal of Kidney Diseases, Vol. 46 No. 4, pp. 642-649.

Joshwa, B., Khakha, D.C. and Mahajan, S. (2012), "Fatigue and depression and sleep problems among hemodialysis patients in a tertiary care center", Saudi Fournal of Kidney Diseases and Transplantation, Vol. 23 No. 4, p. 729.

Kao, T., Lai, M., Tsai, T., Jan, C., Chie, W. and Chen, W. (2009), "Economic, social, and psychological factors associated with health-related quality of life of chronic hemodialysis patients in Northern Taiwan: a multicenter study", Artificial Organs, Vol. 33 No. 1, pp. 61-68.

Katon, W., Lin, E.H.B. and Kroenke, K. (2007), "The association of depression and anxiety with medical symptom burden in patients with chronic medical illness", General Hospital Psychiatry, Vol. 29 No. 2, pp. 147-155.

Kimmel, P.L., Weihs, K. and Peterson, R.A. (1993), "Survival in hemodialysis patients: the role of depression", fournal of the American Society of Nephrology: Fasn, Vol. 4 No. 1, pp. 12-27.

Levy, N.B. (2008), "What is psychonephrology?", fournal of Nephrol, Vol. 21, pp. S51-3.

Li, Y.-N., Shapiro, B., Kim, J.C., Zhang, M., Porszasz, J. and Bross, R. et al. (2016), "Association between quality of life and anxiety, depression, physical activity and physical performance in maintenance hemodialysis patients", Chronic Diseases and Translational Medicine], Vol. 32 No. 2, pp. 110-119, available at: www.ncbi.nlm.nih.gov/pubmed/ 29063031
Lovibond, S.H. and Lovibond, P.F. (1995), Manual for the Depression Anxiety Stress Scales, 2nd ed., Psychology Foundation, Sydney.

Lufiyani, I., Zahra, A.N. and Yona, S. (2019), "Factors related to insomnia among end-stage renal disease patients on hemodialysis in Jakarta, Indonesia", Enfermería Clinica [Clínica], Vol. 29, available at: www.sciencedirect.com/ science/article/pii/S113086211930275X

Moussa, M.T., Lovibond, P., Laube, R. and Megahead, H.A. (2017), "Psychometric properties of an Arabic version of the depression anxiety stress scales (DASS)", Research on Social Work Practice, Vol. 27 No. 3, pp. 375-386.

Müller, H., Gwinner, W., Haltenhof, H., Kornhuber, J. and Maler, J.M. (2010), "Psychological risk factors of kidney transplant patients", Kidney International, Vol. 77 No. 9, p. 833.

Parker, K.P. (2003), "Sleep disturbances in dialysis patients", Sleep Medicine Reviews, Vol. 7 No. 2, pp. 131-143.

Saeed, Z., Ahmad, A.M., Shakoor, A., Ghafoor, F. and Kanwal, S. (2012), "Depression in patients on hemodialysis and their caregivers", Saudi Fournal of Kidney Diseases and Transplantation, Vol. 23 No. 5, p. 946.

Tavallaii, S.A., Ebrahimnia, M., Shamspour, N. and Assari, S. (2009), "Effect of depression on health care utilization in patients with end-stage renal disease treated with hemodialysis", European fournal of Internal Medicine, Vol. 20 No. 4, pp. 411-414.

Turkistani, I., Nuqali, A., Badawi, M., Taibah, O., Alserihy, O., Morad, M., Kalantan, M. (2014), "The prevalence of anxiety and depression among end-stage renal disease patients on hemodialysis in Saudi Arabia", Renal Failure, Vol. 36 No. 10, pp. 1510-1515.

Walker, S., Fine, A. and Kryger, M.H. (1995), "Sleep complaints are common in a dialysis unit", American fournal of Kidney Diseases, Vol. 26 No. 5, pp. 751-756.

Weissman, M.M., Bland, R.C., Canino, G.J., Faravelli, C., Greenwald, S., Hwu, H.-G., Joyce, P.R., Karam, E.G., Lee, C.-K., Lellouch, J., Lépine, J.-P., Newman, S.C., RubioStipec, M., Wells, J.E., Wickramaratne, P.J., Wittchen, H.-U. and Yeh, E.-K. (1996), "Cross-national epidemiology of major depression and bipolar disorder", Fama: The fournal of the American Medical Association, Vol. 276 No. 4, pp. 293-299.

\section{Corresponding author}

Abdulwahab Aqeeli can be contacted at: aqeeli.a@gmail. com 